\title{
SARS-CoV-2 infection in an infant with non- respiratory manifestations: a case report
}

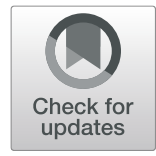

\author{
${\text { Muhammad } \text { Adel }^{1 *} \text { (D) and Ahmed Magdy }}^{2}$
}

\begin{abstract}
Background: Coronavirus disease (COVID-19) presents in children usually with less severe manifestations than in adults. Although fever and cough were reported as the most common symptoms, children can have non-specific symptoms. We describe an infant with aplastic anemia as the main manifestation.

Case presentation: We describe a case of SARS-CoV-2 infection in an infant without any respiratory symptoms or signs while manifesting principally with pallor and purpura. Pancytopenia with reticulocytopenia was the predominant feature in the initial laboratory investigations, pointing to aplastic anemia. Chest computed tomography surprisingly showed typical findings suggestive of SARS-CoV-2 infection. Infection was later confirmed by positive real-time reverse transcription polymerase chain reaction assay (RT-PCR) for SARS-CoV-2.

Conclusions: Infants with COVID-19 can have non-specific manifestations and a high index of suspicion should be kept in mind especially in regions with a high incidence of the disease. Chest computed tomography $(C T)$ and testing for SARS-CoV-2 infection by RT-PCR may be considered even in the absence of respiratory manifestations.
\end{abstract}

Keywords: COVID-19, Pediatrics, Pancytopenia, Case report

\section{Background}

The new coronavirus was first reported in Wuhan, China, in December 2019, as the cause of severe pneumonia [1]. The virus is named SARS-CoV-2 and causes a disease called COVID-19 [2]. In March 2020, the WHO has declared it as a pandemic [3]. Although COVID-19 can affect all age groups, it presents in children usually with milder manifestations than in adults and may cause non-specific symptoms [4]. However, infants, in particular, were found to be vulnerable to SARS-CoV-2 infection [5]. In China, a cohort of 171 confirmed COVID-19 cases in children revealed that fever, cough, and pharyngeal erythema were the most common manifestations [6]. In Italy, The Coronavirus Infection in Pediatric Emergency Departments (CONFIDENCE) study [7] that involved 100 Italian children with

\footnotetext{
*Correspondence: mas19@fayoum.edu.eg; drmadel11@gmail.com 'Pediatric Department, Faculty of Medicine, Fayoum University Children's Hospital, Fayoum, Egypt

Full list of author information is available at the end of the article
}

COVID-19 reported similar results with fever and cough being the most common symptoms.

None of the cases described by the CONFIDENCE study [7] nor by Lu et al. [6] were reported to have pancytopenia. A cytokine profile resembling secondary hemophagocytic lymphohistiocytosis (sHLH) is found to be associated with some cases of COVID-19 [8]. So, sHLH could be triggered by COVID-19. We describe here a COVID-19 case of an infant presenting with pallor and purpura as the main symptoms without respiratory symptoms.

\section{Case presentation}

The patient is a 71-day-old, full-term, previously healthy male infant. Before admission, he developed a low-grade fever and two vomiting episodes for 2 days. He received paracetamol as outpatient then fever and vomiting subsided. No other drugs were taken. Three days later, he developed acute onset of pallor and purpura which were the principal presentations to the emergency department on 28 April 2020. No respiratory symptoms or any other 
symptoms were reported. His general condition was good. He had sinus tachycardia with a heart rate of 176/ min but with normal respiratory rate, capillary refill time, blood pressure, and oxygen saturation. He had no dysmorphic features or any skeletal anomalies. His chest examination was normal with no respiratory distress. However, hepatosplenomegaly was detected. No focal signs of infection were found. His initial laboratory testing (Table 1) revealed marked pancytopenia with low reticulocytic count $(0.2 \%)$. The direct blood film showed no abnormal cells. A bone marrow aspirate was performed and found to be hypocellular without abnormal cells. Other tests showed coagulopathy, mildly elevated liver enzymes, markedly elevated ferritin, elevated triglycerides. Kidney function tests were normal and blood and urine cultures were negative. Bone marrow biopsy or liver biopsy were not done. Patient received supportive therapy with transfusion of packed RBCs for three times to correct his anemia, and he also received fresh frozen plasma for three times to correct coagulopathy. $\mathrm{He}$ was admitted for 6 days at pediatric ward. During admission, he had fever for 2 days. However, there were no cough, pharyngeal erythema, or any other respiratory symptoms or signs all through during the admission period. Vital signs were normal without any deterioration in his general condition. Although the patient had no respiratory symptoms or signs of COVID-19, a chest computed tomography $(\mathrm{CT})$ was performed particularly in the setting of increasing incidence of COVID-19 in Egypt at that time. It was done on day 4 of admission which surprisingly revealed (Fig. 1) multiple scattered consolidative patches scattered at both lung fields, being distributed mainly posteriorly, implicating posterior and apico-posterior segments of right upper lobe, lateral lingular segment, and to less extent, the lateral basal segment of left lower lobe. Mild left pleural effusion was also noted. CO-RADS is a radiological

Table 1 Laboratory tests

\begin{tabular}{|c|c|c|c|c|c|}
\hline & $\begin{array}{l}28 / 4 \text { morning } \\
\text { sample }\end{array}$ & $\begin{array}{l}\text { 28/4 Evening } \\
\text { sample }\end{array}$ & $29 / 4$ & $1 / 5$ & $3 / 5$ \\
\hline Hemoglobin (g/dL) & 2.9 & 2.8 & $\begin{array}{l}6.3 \text { After PRBCs } \\
\text { transfusion }\end{array}$ & & $\begin{array}{l}10.5 \text { After PRBCs } \\
\text { transfusion }\end{array}$ \\
\hline$M C V(f L)$ & 81 & 88.9 & & & 78.7 \\
\hline $\mathrm{MCH}(\mathrm{pg})$ & 26.4 & 31.1 & & & 26.6 \\
\hline Corrected reticulocytic count \% & $0.4 \%$ & $0.2 \%$ & & & \\
\hline White blood cell count $\left(\times 10^{9} / \mathrm{L}\right)$ & 2.7 & 4.94 & 4.19 & & 2.39 \\
\hline Lymphocytic count $\left(\times 10^{9} / \mathrm{L}\right)$ & $2.29(85 \%)$ & $4.25(86 \%)$ & & & \\
\hline Neutrophil count $\left(\times 10^{9} / \mathrm{L}\right)$ & $0.134(5 \%)$ & $0.197(4 \%)$ & & & \\
\hline Monocyte count $\left(\times 10^{9} / \mathrm{L}\right)$ & $0.27(10 \%)$ & $0.494(10 \%)$ & & & \\
\hline Platelet count $\left(\times 10^{9} / \mathrm{L}\right)$ & 40 & 36 & 44 & & 5 \\
\hline Bone marrow aspirate & & & Hypocellular & & \\
\hline C-reactive protein (mg/L) & 3 & & & & 6 \\
\hline Erythrocyte sedimentation rate $(\mathrm{mm} / \mathrm{h})$ & 16 & & & & \\
\hline Ferritin $(\mathrm{ng} / \mathrm{mL})$ & & & & 5983 & \\
\hline Triglycerides (mmol/L) & & & & 5.6 & \\
\hline Alanine aminotransferase $(U / L)$ & 73 & & 79 & & 34 \\
\hline Aspartate aminotransferase (U/L) & 96 & & 110 & & 44 \\
\hline International normalized ratio (INR) & & & 4.13 & 1.1 & 1.2 \\
\hline Albumin (g/L) & 38 & & & & 39 \\
\hline EBV VCA IgM & & & Negative & & \\
\hline CMV IgM & & & Negative & & \\
\hline Blood culture & Obtained & & & No growth & \\
\hline $\mathrm{pH}$ & 7.54 & & & & \\
\hline $\mathrm{pCO}_{2}(\mathrm{mmHg})$ & 26 & & & & \\
\hline $\mathrm{HCO}_{3}(\mathrm{mmol} / \mathrm{L})$ & 24.7 & & & & \\
\hline RT-PCR for SARS-CoV-2 & & & & Obtained & Positive \\
\hline
\end{tabular}

Abbreviations: $M C V$ mean corpuscular volume, $M C H$ mean corpuscular hemoglobin. EBV VCA Epstein-Barr virus-viral capsid antigen antibody, $C M V$ cytomegalovirus, PRBCs packed red blood cells 
classification for the possibility of COVID 19 with the level of suspicion increasing from very low (CO-RADS 1) to very high (CO-RADS 5) [9]. RT-PCR-proven SARS-CoV-2 infection at the time of examination is classified as category CO-RADS 6 [9]. The patient had category CO-RADS 5 based on CT findings only. The infant was immediately isolated and tested for SARS-CoV-2 by RT-PCR of nasopharyngeal swab that was surprisingly positive, confirming the infection and putting him in the category CO-RADS 6. Patient was then referred to an isolation hospital for COVID19 cases. He developed vasoplegic shock and died.

\section{Discussion}

This report describes an interesting case of SARS-CoV-2 infection that presented with fever, pallor, and purpura as the initial presentation in the absence of any respiratory symptoms or signs. COVID-19 presents in children usually with milder manifestations than in adults [4]. However, young children, especially infants, were found to be vulnerable to SARS-CoV-2 infection with a higher proportion of severe cases than any other pediatric age groups [5]. COVID-19 most commonly presents with a spectrum of signs and symptoms ranging from completely asymptomatic to symptoms of acute upper respiratory tract infection such as fever, cough, sore throat, rhinorrhea, and shortness of breath. In more severe cases, patients can have respiratory failure, shock, coagulopathy, and renal injury [5]. Regarding our patient's clinical presentation, it was non-specific, having no respiratory symptoms or signs all during the period of hospitalization. However, this case had principally features of aplastic anemia with acute onset of pallor and purpura following fever and vomiting. Cai et al. [10] described five cases of COVID-19 in children that also presented non-respiratory manifestations as the first manifestation.

The finding of pancytopenia with reticulocytopenia and hypocellular bone marrow in this case was the guide toward a diagnosis of aplastic anemia (AA). Drug intake, viral infection, HLH, malignancy, bone marrow infiltration by a storage disorder, and inherited bone marrow failure syndromes (IBMFS) were the main suspected causes of AA in this case. Serology markers of EpsteinBarr virus (EBV) and cytomegalovirus (CMV) were negative. There was no history of drug intake prior to the presentation apart from paracetamol. Similarly, there were no features to suggest IBMFS (as there were no any developmental delay, family history of cytopenias or congenital anomalies, osteopetrosis, short stature, limb anomalies, or any other anomalies). Features suggestive of HLH in this patient were markedly elevated ferritin, high triglycerides, and pancytopenia in addition to clinically detected hepatosplenomegaly and fever. So, a diagnosis of AA secondary to HLH was considered.

Neither the Italian CONFIDENCE study [7] nor Lu et al. [6] in China reported COVID-19 cases with pancytopenia. Both studies reported only leukopenia and/or thrombocytopenia in some cases. A cytokine profile
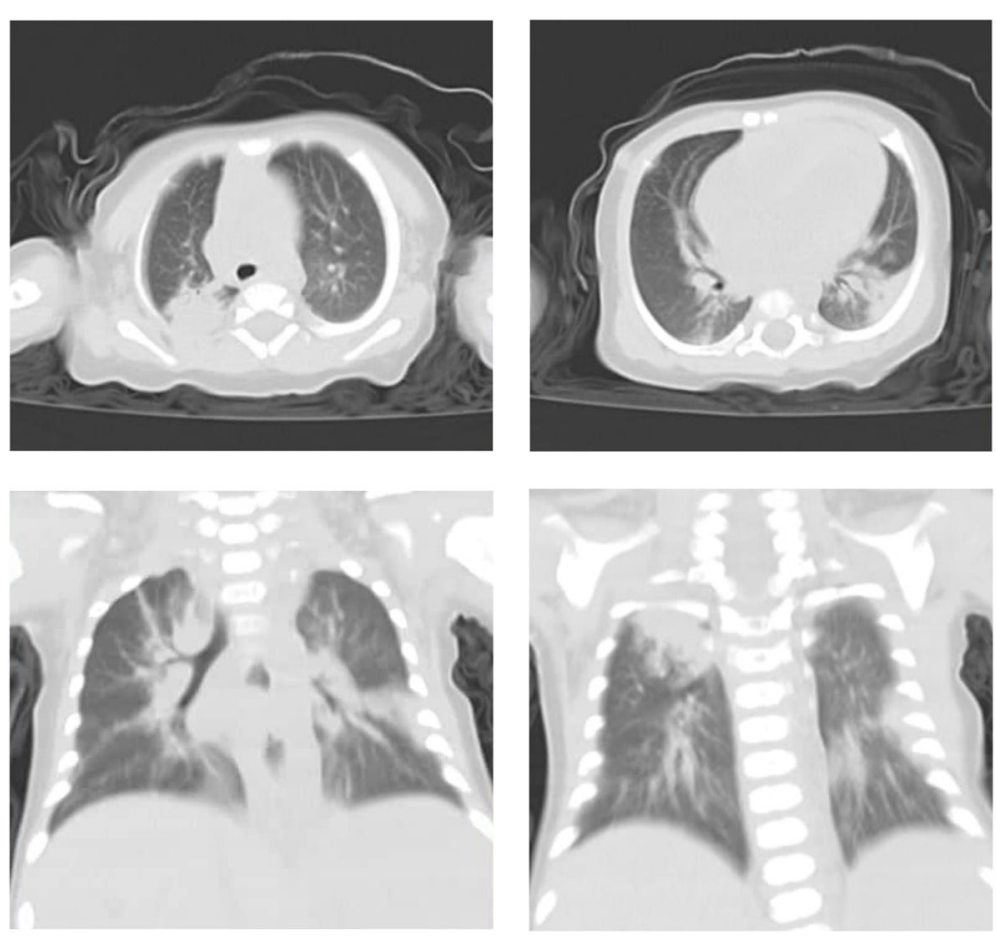

Fig. 1 Chest $C T$ findings 
resembling $\mathrm{sHLH}$ is found to be associated with COVID-19 in some cases which is characterized by increased interleukin (IL)-2, IL-7, granulocyte colony stimulating factor, interferon- $\gamma$ inducible protein 10 , and many other factors [8]. This may indicate that sHLH could be triggered by COVID-19. It was reported that viral infections may trigger secondary forms of HLH [11]. Pancytopenia represents a great challenge for the diagnosis of COVID-19 because the clinical manifestations of respiratory affection were absent.

As regards the CT chest findings, this case report suggests that infants with SARS-CoV-2 infection may not exhibit respiratory symptoms and signs even in the presence of radiological findings of pneumonia. Similarly, Lu et al. [6] reported that out of 171 children with confirmed SARS-CoV-2 infection, only 12 had radiologic findings of pneumonia without having any symptoms of infection. Cai et al. [10] also reported five children with COVID-19 who had radiological findings of pneumonia in chest CT without having any respiratory symptoms or signs.

This case highlights that aplastic anemia due to sHLH can be the initial and the principal presenting feature of COVID-19. Reliance on respiratory symptoms and signs only for testing will easily miss cases in whom these symptoms and signs are absent while fever alone or symptoms of other organ system affection are the first presenting features. As the predominant clinical manifestations of COVID-19 can vary from one patient to another, one should keep a high index of suspicion, especially in the setting of increasing incidence of COVID-19 cases.

\section{Conclusion}

SARS-CoV-2 infection in infants should be kept in mind in those presenting with non-specific clinical picture such as fever and vomiting, especially in epidemic areas. Chest CT, in addition to nucleic acid testing for SARSCoV-2, may be considered for diagnosing cases regardless of the presence or absence of respiratory symptoms or signs, particularly in regions with increasing incidence of COVID-19 cases. We are still in need of further reporting of the clinical presentation pattern of COVID19 cases in children.

\footnotetext{
Abbreviations

SARS-CoV-2: Severe acute respiratory syndrome coronavirus 2; COVID19: Coronavirus disease 2019; WHO: World Health Organization; sHLH: Secondary hemophagocytic lymphohistiocytosis; HLH: Hemophagocytic lymphohistiocytosis; CT: Computed tomography; RTPCR: Real-time reverse transcription polymerase chain reaction assay; AA: Aplastic anemia; IL: Interleukin; EBV: Epstein-Barr virus; CMV: Cytomegalovirus
}

\section{Authors' contributions}

MA collected data, conceptualized and designed the study, drafted the initial manuscript, reviewed and revised the manuscript. AM collected imaging data, carried out the imaging data analysis, reviewed and revised the manuscript. All authors read and approved the final manuscript.

\section{Funding \\ None.}

Availability of data and materials

Not applicable.

Ethics approval and consent to participate

This study was conducted in accordance with the fundamental principles of the Declaration of Helsinki.

\section{Consent for publication}

Written informed consent from child's parent for publication was obtained.

\section{Competing interests}

All authors declare that they have no competing interests.

\section{Author details}

'Pediatric Department, Faculty of Medicine, Fayoum University Children's Hospital, Fayoum, Egypt. ${ }^{2}$ Radiology Department, Faculty of Medicine, Fayoum University Hospital, Fayoum, Egypt.

Received: 28 May 2020 Accepted: 9 December 2020

Published online: 25 January 2021

\section{References}

1. The Novel Coronavirus Pneumonia Emergency Response Epidemiology Team (2020) The epidemiological characteristics of an outbreak of 2019 novel coronavirus diseases (COVID-19)-China, 2020. China CDC Weekly 2(8): 113-122. https://doi.org/10.3760/cma.j.issn.0254-6450.2020.02.003

2. World Health Organization (2020) https://www.who.int/emergencies/ diseases/novel-coronavirus-2019/technical-guidance/naming-thecoronavirus-disease-(covid-2019)-and-the-virus-that-causes-it. Accessed 8 May 2020.

3. World Health Organization (2020) https://www.who.int/dg/speeches/detail/ who-director-general-s-opening-remarks-at-the-media-briefing-on-covid-1 9\%2D\%2D-11-march-2020. Accessed 8 May 2020.

4. Lu Q, Shi Y (2020) Coronavirus disease (COVID-19) and neonate: what neonatologist needs to know. J Med Virol. https://doi.org/10.1002/jmv.25740

5. Dong Y, Mo X, Hu Y et al (2020) Epidemiology of COVID-19 among children in China. Pediatrics 145(6):e20200702

6. Lu X, Zhang L, Du H, et al. (2020) SARS-CoV-2 infection in children. N Engl J Med. https://doi.org/10.1056/NEJMc2005073

7. Parri N, Lenge M, Buonsenso D (2020) Children with Covid-19 in pediatric emergency departments in Italy. N Engl J Med. https://doi.org/10.1056/ NEJMc2007617

8. Huang C, Wang Y, Li X et al (2020) Clinical features of patients infected with 2019 novel coronavirus in Wuhan, China. Lancet 395:497-506

9. Prokop M, Everdingen W, Vellinga T, et al. (2020) CO-RADS-a categorical CT assessment scheme for patients with suspected COVID-19: definition and evaluation. Radiology. doi: https://doi.org/10.1148/radiol.2020201473

10. Cai X, Ma Y, Li S et al (2020) Clinical characteristics of 5 COVID-19 cases with non-respiratory symptoms as the first manifestation in children. Front. Pediatr. 8.258. https://doi.org/10.3389/fped.2020.00258

11. Janka G, Elinder G, Imashuku S et al (1998) Infection-and malignancy associated hemophagocytic syndromes: Secondary hemophagocytic lymphohistiocytosis. Hematol Oncol Clin North Am. 12:435-444

\section{Publisher's Note}

Springer Nature remains neutral with regard to jurisdictional claims in published maps and institutional affiliations. 